\title{
Communautaires Mesurer les Retombées
}

La cartographie des actifs de la communauté, c'est le processus par lequel on identifie, pour les répertorier ensuite, les actifs matériels et sociaux de la ville, depuis des industries majeures jusqu'à des groupes culturels. C'est un outil de planification permettant aux municipalités et aux leaders communautaires de se donner une nouvelle perspective sur les actifs communautaires existants. Ceuxci contribuent à améliorer la qualité de vie et à former l'environnement matériel et social de n'importe quelle ville. Les actifs communautaires peuvent comprendre le milieu naturel, les structures physiques, les valeurs et les connaissances sociales et culturelles, la fonction publique, les emplois et les entreprises. Après avoir identifié ce qu'il y en a déjà dans la communauté, le processus de planification stratégique procède à déclencher de nouveaux actifs jusque-là insuffisamment utilisés. Pour qu'il se trouve dans une population diverse les conditions d'investissement, d'attachement et d'appartenance, il faut un grand nombre d'intervenants prêts à y participer.

Une infrastructure de soutien peut être intégrée dans les actifs matériels communautaires existants ou bien exploitée par des intéressés connus. Dans ce contexte, cela veut dire la capacité des leaders municipaux d'aménager une structure existante telle qu'un hôpital, une école ou une bibliothèque ainsi que de former et des employeurs et des travailleurs de première ligne à faire face à des questions de diversité tout en favorisant l'inclusion. Pour attirer et retenir des nouveaux arrivants, les adaptations de l'entreprise peuvent se présenter sous forme d'une politique d'embauche inclusive ou de l'offre des cours de langue ou de la disponibilité des directives et des politiques en multiples langues.

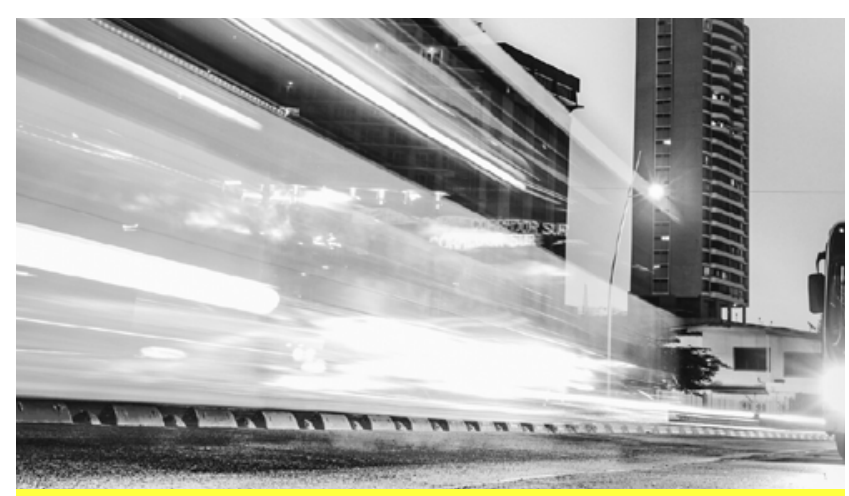

\section{Liste possible d'intervenants, d'industries et d'organismes locaux}

> Développement économique municipal

> Agences de développement économique locales ou régionales

> Bureau municipal d'accueil de nouveaux arrivants

$>$ Chambre de commerce

$>$ Centres pour les petites entreprises

> Associations vouées à l'amélioration des entreprises au centre-ville

> Centres d'emploi et d'éducation

$>$ Employeurs locaux

> Conseil scolaire du district - enseignement international

> Collèges communautaires - enseignement international

> Universités - enseignement international

> La coopérative de crédit ou linstitution financière locale

> Organismes desservant les immigrants

> Institutions essentielles, par ex. les hôpitaux, les centres de santé régionaux, les bibliothèques publiques, les musées publics et les galeries d'art publiques

> Tourisme et marquage : les arts et la culture, les sports et les loisirs, les parcs et les biens culturels 